\title{
Exploring The Cuban Blogosphere: Discourse Networks and Informal Politics
}

\author{
Abstract. Despite the rapid growth of a blogosphere literature interested in blogging \\ practices across democratic countries and authoritarian regimes, little is known about \\ Cuban blogs. The current study aims to bridge this gap by specifically looking at 66 \\ blogs from four ideologically diverging Cuban blog platforms. By applying a \\ combination of social network analysis and content analysis techniques, the study \\ investigates structure and content of the Cuban blogosphere. Findings show that blog \\ interactions have developed differently depending on the blogs' ideological \\ orientation although cross-ideological interactions have sometimes emerged. The \\ Cuban blogosphere has extended beyond national borders primarily via diaspora \\ blogs, centering its discourse network on domestic political issues divergent from \\ those available on state- or US-controlled mainstream media.
}

Key words: public sphere, networks, blogosphere, Cuba.

\section{Introduction}

In March 2011, the Cuban television program Razones de Cuba aired the series “Cyberwar," focused on US cyber security policies and cyber espionage tactics ${ }^{\mathrm{i}}$. At the core of the program were so-called mercenarios or dissident bloggers. "In the island there is a new type of counterrevolution organized by bloggers. [...] These cyber projects, promoted by cyber mercenaries, are instruments that have been fabricated [by the US] to create hubs of internal conflicts through the use of information and communication technologies," said the narrator.

"Cyberwar" launched the blogosphere in the traditional media system, exposing it to the mainstream Cuban audience. No matter the framing of the blogosphere delivered by "Cyberwar," the program turned blogs into a new topic of 
public interest and public debate, beyond the boundaries of the extremely limited online Cuban audience. This study addresses exactly the development of the Cuban blogosphere from its emergence as a limited, constrained phenomenon in 2007 until its official entering the mainstream political debate in 2011.

Social movement and media literatures have focused on several examples of blogospheres in authoritarian contexts, e.g., Iran (Kelly and Etling, 2007), Burma (Chowdhury, 2008), Arabic countries (Etling et al., 2010). Those studies investigate the extent to which blogging may have contributed to the emergence of new forms of informal political debate and participation, where offline public sphere dynamics were constrained by state-centered censorship and/or instances of social unrest. However, little attention has been drawn to the Cuban context.

Cuba is a very interesting case study for three main reasons. First, its civil society is subjected to the violation of political rights and civil liberties; second, Internet access is exceptionally limited and state-controlled; third, a Cuban blogosphere emerged in April 2007 and since then the number of Cuban blogs has kept increasing (Henken, 2011; Hoffman, 2011; Price, 2011).

This study investigates the development of the Cuban blogosphere as a space of informal politics, from its silent start in 2007 to its entering the mainstream political debate on Razones de Cuba in 2011.The analysis has two main foci: the structural features of the Cuban blogosphere and its periphery—with specific interest in structural potential for cross-ideological interactions - and the blogosphere discourse practices possibly diverging from those in mainstream media. By applying a combination of social network analysis and content analysis techniques, the study focuses on 66 blogs from four ideologically diverging blog platforms, namely, Voces Cubanas, Havana Times, Bloggers Cuba, and La Joven Cuba. 
In the following sections, the article discusses theoretical contributions on the relationship between public sphere dynamics and Internet use, specifically focusing on blogging practices in authoritarian regimes. Next, data and methods are described. The remainder of the study specifically develops two primary lines of investigation: a longitudinal social network analysis of the Cuban blogosphere and its periphery, and an exploration of Cuban bloggers and blogging content.

\section{Internet and the public sphere: Ongoing debate.}

The topical debate regarding if and how new media can contribute to the emergence of a regenerated public sphere-in Habermasian terms - has now populated the sociological and media and communication terrains for almost twenty years ${ }^{\mathrm{ii}}$. The question is generally centered on the extent to which new media may truly enable civic agency, given the technological and socio-economic constraints that characterize democratic countries and authoritarian regimes differently.

Two main pathways may be identified in the literature: early research tried to investigate — theoretically and empirically_how Habermas' conceptualization of the public sphere may be more or less directly applicable to the online realm (see, for instance, Dahlberg, 2001; Emden 2012: 66; Schneider, 1997); following studies have used it as an ideal type, a metaphor against which to measure processes of democratization (see Papacharissi, 2008) or elaborate new theorizations for online informal political debate and civic engagement (e.g., Benkler, 2006; Dahlgren, 2000; De Luca and Peeples, 2012; Downey and Fenton, 2003; Fraser, 2007; Papacharissi, $2002)^{\text {iii }}$.

Studies from the second camp, while often focusing on different aspects of the debate on the relationship between new media and democratization, all begin from the assumption that the public sphere should be understood as an ideal realm of social 
life, where personal opinions on public issues can be reciprocally exchanged and discussed, possibly leading to common deliberation. Considering this as an ideal condition, we may advance that new media show potential for the renegotiation of what is private and public, by enabling individuals to break/comment on/diverge from the public agenda determined by institutional news producers ${ }^{\text {iv }}$.

In his discussion of "civic culture," Dalghren (2005: 148-150) suggests a threefold interpretation of the public sphere concept, based on the identification of its structural, representational, and interactional dimensions. The structural dimension involves the availability and accessibility—subject to social, economic, and political dynamics - of media infrastructures that channel flows of information. The representational dimension refers to the way in which different publics are more or less represented in public debates. The interactional dimension recalls the idea of reciprocity, that is, the importance of the emergence of dialogical debates for healthy public sphere dynamics. Thus, the latter two dimensions are mostly dependent on the former, that is, representational and interactional processes directly depend on structural availability. Hence, if we aim to study if and to what extent new media may enable civic engagement—and possibly lead to public deliberation—we need to look back at the infrastructure of the media system that we intend to analyze, its internal, micro-level features (e.g., architecture, directional flows of information), and external, macro-level constraints (i.e., political and economic direct and indirect control).

Benkler (2006) centers his theorization of the "networked public sphere" on what Dalghren (2005) calls the "structural dimension" of the public sphere, that is, he investigates the networked structure of the Internet to measure the extent to which it may enable more civic agency than mainstream media systems. The idea is that network topology theory, or the mapping of the potential Internet information 
pathways, can show that the Internet enables more representational and interactional processes than traditional media systems (Benkler, 2006: 247) ${ }^{\mathrm{v}}$. Benkler's position is not technologically deterministic, but it certainly asserts a positive relationship between Internet usage and potential for civic action. However, early criticisms to the democratizing effects of the Internet have drawn attention to the still uneven levels of Internet access, the lack of reciprocity in most online communication (Bohman, 2004: 135; Papacharissi, 2008: 234-5), the online information overload that leads to the fragmentation of online publics (Dahlberg, 2007; Habermas, 2007: 423-4 n. 3; Sustein, 2001), the polarization of discourse practices (Benkler, 2006: 235), and the commercialization of online channels of information and communication (Noam, 2005; Papacharissi, 2008: 235-6). Second-generation criticisms have also focused on dynamics of centralization, or the way in which only few websites receive most readers' attention, while many more are never visited by anyone (Benkler, 2006: 2356; Hindman, 2009).

To counter the first criticisms, one may advance that Internet penetration rates are constantly increasing and that the academic literature is still seeking a way to measure the new forms of online reciprocity allowed by contemporary social media.

Benkler's counter argument to the remaining criticisms centers on network behavior and stresses on the "filtering, accreditation, and synthesis mechanisms" (2006: 271) allowed by the network topology of the Internet architecture, and nonexistent in the one-way structure of the traditional mass media. Benkler pushes his argument even further by saying that "because of these emerging systems, the networked information economy is solving the information overload and discourse fragmentation concerns without introducing the distortion of the mass-media model" 
(2006: 271) $)^{\mathrm{vi}}$. However, the list of challenges regarding the democratizing potential of the Internet lengthens when we analyze authoritarian regimes.

\subsection{Structural availability and online civic agency in authoritarian regimes}

The 2010 outburst of the wave of protests that later came to be known as "Arab spring," revitalized the already growing discussion on the role and consistence of online, informal political debates leading to civic agency in authoritarian regimes. Previous cases already attracted scholarly attention, namely the 2004 "Orange revolution" in Ukraine (Goldstein, 2007), the 2007 "Saffron Revolution" in Burma (Chowdhury, 2008), and the 2009 “Twitter revolutions" in Moldova (Morozov, 2009a, 2009b) and Iran (Morozov, 2009c; Rahimi, 2011). Most of this research primarily focuses on what existed online before and during the protests, that is, what discourse practices occurred online that may have eased the emergence of informal political debates, eventually leading to the outburst of street protests. Yet, for sparse and interactional informal political debates to occur, which communication structures were factually available in those authoritarian contexts?

There are different levels of state intervention on Internet freedom, in factsave for North Korea — total ban has progressively shifted into different strategies of Internet control. King et al. (in press), for instance, show that Chinese social media censorship follows a specific strategy: individuals are free to use Chinese social media to post messages against the state, leaders, or policies. Posts that are censored are those that bolster discussions potentially leading to collective action. Countries like Saudi Arabia and the United Arab Emirates employ technologically advanced censorship schemes for the Internet and government-funded private Internet service providers limit access to websites considered as anti-Islamic (Kalathil and Boas, 2003: 103-120). In Cuba, since 1996, the government has controlled the development 
of the Internet in a way to prioritize its use in certain areas (e.g., public health, education) and minimize its politically challenging potential (Kalathil and Boas, 2003: 43-69).

In the countries where social disruption occurred — eased by digital networking — other last minute tactics of dissent management were used. On 01 September 2007, the Burmese government shut down the Internet and suspended most mobile communication in the attempt to stop news on protests, and protest repression from within Burma to leak to the outside world (Chowdhury, 2008: 9). In Iran, after the 2009 presidential elections, many websites were blocked and activists needed to use proxies provided by the diasporas to access those sites (Rahimi, 2011: 168). In January 2011 in Tunisia, immediately after the resignation of dictator Ben Ali, Twitter use suddenly declined when security forces tried to interfere with communication networks after days in which more than a thousand Tunisians had been tweeting the protests (Howard et al., 2011: 11).

Yet, despite the abovementioned tactics of online dissent management, in most authoritarian regimes, and especially in those where uprisings have occurred in the past decade, blogospheres have emerged as feasible communication structures for online civic agency via sparse and interactional informal political debate (Chowdhury, 2008; Etling et al., 2010; Henken, 2011; Radsch, 2008; Rahimi, 2011; Zhuo, 2009).

\subsection{Blogospheres in authoritarian regimes}

Research specifically centered on the dialogical potential of blogs started examining them within topically oriented or interest-based clusters, rather than as individual artifacts. Hence, blogospheres instead of individual blogs became a subject of investigation. Findings showed that groupings of blogs within blogospheres are densely interconnected, central blogs are over connected, conversational dynamics are 
present though sporadic (Adamic and Glance, 2005; Herring et al., 2005), and "bridge bloggers," or bloggers who bridge separate blogospheres, play a central role in extending cultural communities (Zuckerman, 2008). Moreover, analyses of blogospheres in non-Anglo American democratic contexts have shown that cultural values are often reproduced in linking practices (Moe, 2011; Park and Kluver, 2009), and that over time structural changes may affect network interactions (Chang Wooyoung and Park, 2012).

Case studies of blogospheres in authoritarian regimes draw attention to specific elements. Chowdhury's (2008) study shows that during the Saffron revolution the Burmese blogosphere flooded into the transnational blogosphere to spread information and find support abroad. Early research on the Iranian blogosphere has shown that blogging in Iran has gradually become a new speech genre (Doostdar, 2004), while more recent studies have shown how before the 2009 protests the Iranian blogosphere provided access to alternative news and allowed citizens to express dissent (Rahimi, 2011). Radsch (2008) investigates the diversification and fragmentation of the Egyptian blogosphere after 2006. In their study of the Arabic blogosphere, Etling et al. (2010) demonstrate a level of variability in the way in which blog discourse practices are embedded in political contexts. Their mapping shows clear local clusters in the overall blogosphere and uncovers bridging practices toward transnational web 2.0 sites (e.g., YouTube), and mainstream pan-Arabic media content.

Overall, blogosphere analyses show that blogging often leads to a strong renegotiation of public and private discourse practices, it may generate areas of dense and highly conversational interactions or isolate unpopular topics, it may cut across national borders toward transnational media audiences, it may interact with other web 
2.0 sites and with mainstream media agendas, and it may structurally change over time. The question remains of how the study of these characteristics may inform an analysis of civic agency, that is, how these different elements can be tested against the original metaphor of the public sphere.

\subsubsection{Cuban blogosphere}

Blogosphere research applied to authoritarian contexts has followed a case-by-case approach, primarily providing exploratory results. The more or less explicit aim in all case studies remains to test the potential democratizing effects of blogging, in terms of enabling sparse and dialogical informal political debate. While it would be difficult to forecast the outburst of social disruption on the basis of an analysis of online, informal political debate, it is of central interest to investigate how-given authoritarian constraints — such agency may develop online. For example, while Etling et al.'s (2010) study of the Arabic blogosphere did not foresee the Arab spring, it provided a meaningful insight into the forms of informal political debate and the practices of civic agency mushrooming in the Arab world at the dawn of the Arab spring. The present study specifically suggests that a blogosphere analysis informed by Dahlgren's threefold take on the original public sphere ideal type and Benkler's analytical approach to structural availability, may provide a systematic exploratory investigation of civic agency generated via online, informal political debates.

Cuba is a unique case in terms of Internet penetration and literacy. Since the 1959 Revolution, the country has been ruled by an authoritarian state that, apart from a series of limited economic reforms in the 1990s, has only allowed few liberalization policies with the advent of Raul Castro as head of state in 2008. The state has full control on all media outputs, save for the US-funded radio and TV Marti's programs sent from Florida. On one hand, the Cuban civil society is "not free" in terms of 
political rights and civil liberties (Kelly et al., 2012). On the other, Cuba is in the bottom ranking of the ICTs Development Index (IDI) access and use sub-indexes, but it is in the top ranking of the IDI skills sub-index (ITU, 2012). In other words, despite extreme obstacles to access ICTs, Cubans have extremely high ICT skills.

The Internet was introduced to Cuba in 1996. According to the Law decree 209 of 1996, Cuban authorities have monitored its development so as to limit it to specific public sectors, such as official institutions and state companies, which in most cases can only access domestic networks. Nevertheless, the Internet has gradually become central to the emergence of new communication practices in the country, via the limited access that people may get through work, hotels, hospitals, and black markets (Price, 2011: 40). Hoffman (2011) highlights three main forms of Internet use that emerged in Cuba during the 2000s: digital recording of alternative cultural activities uploaded on the Web to find audiences, email exchanges for horizontal forms of communication, and blogging. The state has total control on Internet service providers, hence in 2007 the first "dissident" blog-Generation $Y$, by Yoani Sanchez-was established on a server outside the country. While mainly unknown in Cuba, Generation $Y$ gained much international attention, to the point that in 2008 Sanchez was awarded the Ortega y Gasset prize in digital journalism and was nominated among the 100 most influential people of the world by Time magazine. Since 2007, a growing number of independent bloggers have followed Sanchez's path by launching personal blogs.

Given the growing popularity of Generation $Y$, and the emergence of a "dissident blogosphere," state authorities activated a new strategy of dissent management: Cuba's University of Informatics Sciences was given the task to counter online dissent, hence "a number of official blogs emerged as top-down initiatives that 
take on the guise of non-state sites or individualized blogs to gain credibility in its outreach to an international public" (Hoffman, 2011: 21). Henken (2011) provides a first general investigation of the Cuban blogosphere and identifies four "tribes" of blogs, located on four different blog platforms, that hold distinctive ideological orientations on the dissident/revolutionary continuum: Voces Cubanas, Havana Times, Bloggers Cuba, and La Joven Cuba. Henken's (2011) study demonstrates that, despite holding different ideologies, the bloggers within these tribes all stress on their independence and legitimacy: those opposing state views proclaim their independence from US influence, or their not being mercenarios (i.e., mercenaries); those who are more state aligned stress on being independent from the government, or on not being oficialistas (i.e., party liners). Bridges appear to emerge among the four tribes that would start loosening the dynamics of polarization (Henken, 2011:183).

The existing research on Cuban blogs provides a first insight into the Cuban blogosphere but skims over matters of structural availability at the micro-level, that is, the way in which the Cuban blogosphere provides specific pathways for representational and interactional dynamics. This study analyzes the way in which informal political debate is emerging via representational and interactional communication practices on the networked pathways of the Cuban blogosphere, to show if and to what extent civic agency may develop there. The study is specifically driven by the following research questions:

RQ1: How has the network structure of the Cuban blogosphere developed around cores and peripheries?

RQ2: To what extent is the blogosphere participated and how do blogs bridge to external, transnational audiences? 
RQ3: How within the network is the informal political discourse framed, and to what extent does it lead to dialogical exchanges?

\section{Data and Methods}

The analysis focuses on blogs hosted on the four blog platforms that first populated the Cuban blogosphere: Voces Cubanas, Havana Times, Bloggers Cuba, and La Joven Cuba ${ }^{\text {vii }}$. Voces Cubanas was born in 2004 as the digital magazine Consenso desde Cuba. In 2007, it assumed a profile more similar to that of a blog and started hosting Sanchez's Generacion $Y$, the first of a series of blogs that would mushroom in the following years. The focus of the new platform, Voces Cubanas, was on the emergence of citizen journalism that could offer a critical approach to state authoritarianism (Henken 2011: 174). Havana Times was founded in 2009 as a project aimed at offering an alternative to official media. Its position is of critical support for the Revolution. Its founder, expatriate Circles Robinson, operates it from Nicaragua (Henken 2011: 176). Bloggers Cuba was the first blog platform written with official state consent (Hoffman 2011: 22). It was launched in 2008, but it soon had to face internal disputes, leading to its early closure in 2009 (although individual blogs remained online). It then came back as a collective platform in 2011. The most prominent blogger here is Elaine Diaz, a University of Havana Professor of Communication. La Joven Cuba is slightly different from the previous cases because it constitutes a collective blog, rather than a traditional blog platform. It was founded in 2010 by three young professors of the University of Matanzas-Osmany Sánchez, Harold Cárdenas Lema, and Roberto G. Peralo - and primarily stands in defense of the Revolution. In sum, the four platforms provide a starting point for the representation of different ideological stances toward the state. 
All blogs hosted on the four platforms were initially included in the sample, save for photography ones. Out of the resulting 73 blogs, 7 more had to be excluded because they were inactive for more than six months. Hence, the final sample includes 66 blogs. Given the aim of the study to uncover communication practices and longitudinal dynamics, the sample period for examination was set to one year: 01 July 2011-30 June 2012. Two Spanish-speaking researchers read all the posts published during the sample period and coded data according to a pre-set codebook centered on blogger identities, blog content, and outlinks (i.e., websites linked to by the blogs). More specifically, data on blogger identities comprised: age, gender, occupational status, and location of the blogger. Data on content included general and specific topics covered in the blog over the sample period. Codes for general and specific topics were generated by drawing upon Etling et al.'s (2009) codebook and adjusted to the Cuban context. In particular, for this phase of data collection, the first coder identified the topics covered in the posts of each blog over the sample period and extracted all the excerpts ${ }^{\text {viii }}$ relevant to each topic. The second coder verified the results of coding using input versus output verification, that is, she checked the “correspondence between input (source) and output (code)" (Franzosi, 2004: 78). The links listed in the blogrolls were coded for type and location.

With the data having been coded, a combination of two methods was used to map and analyze the Cuban blogosphere: social network analysis of the linking behavior of the selected Cuban blogs to uncover micro-level structural availability for informal political debates, and content analysis to gather information about the ways in which informal political debate is developing within those available structures. While each of the methods was used for specific purposes, the combination of the two was aimed at providing a comprehensive picture of the Cuban blogosphere in terms 
of discourse networks and informal political debates. On the one hand, it could provide a clear mapping of online networking dynamics between bloggers. On the other, it would go beyond what may appear as a crude mapping of hyperlinking structures and investigate blogging content that could ease the emergence of discourse networks.

\section{Social Network Analysis}

\subsection{Longitudinal Mapping (2008-2011) of the Cuban Blogosphere}

In blogosphere analysis, a first measure of structural availability can be obtained by investigating dynamics of diffusion within a blogosphere, that is, by mapping blogs' origins and linking practices over time. Figures 1 and 2 demonstrate the longitudinal diffusion of the Cuban blogosphere from 2008 to 2011. Nodes stand for blogs, while ties stand for hyperlinks, with their arrowheads indicating the direction of the hyperlinks. The dimension of a node measures a blog's in-degree, that is, the number of links it receives from other blogs. In fact, a blog's in-degree is a measure of its popularity. Different colors stand for different blog platforms, with the color of each tie depending on the color of the node where that tie originates.

[Figure 1 about here] 
[Figure 2 about here] 
In 2008, Voces Cubanas and Bloggers Cuba were already active, but their early blogs generated two very different networks. Generation $Y$ was at the center of a star network of six dissident blogs: it was the most popular node- - hence it received ties from all the others - but it was also linked to other less popular dissident blogs. Voces Cubanas emergent network already showed a high degree of cohesion (i.e., 0.47$)^{\mathrm{ix}}$. The same number of nodes populated Blogger Cuba's network, but those nodes were completely isolated from one another, save for La Polemica Digital that received a link from the blog Artilugios. Hence, in this embryonic phase of the Cuban blogosphere, while dissident bloggers probably knew and interacted with one another, more aligned bloggers were mainly isolated, with Elaine Diaz, blogger of La Polemica Digital, emerging as slightly more popular than the others.

The expansion of the Cuban blogosphere from 2009 to 2011 is marked by a series of interesting developments. Voces Cubanas network progressively grows, with Generation $Y$ remaining the most popular blog, followed by other nodes with high visibility within the network (e.g., Octavo Cerco, Malaletra, Pitacora Cubana). Certain nodes become hubs, that is, they provide links to a high number of other nodes (e.g., Malaletra, Generacion Y, Injusticia Notoria) within or outside Voces Cubanas network. Hence, Voces Cubanas blogs progressively generate the only attentive cluster (Benkler 2006; Etling et al. 2010) of the blogosphere, that is, the only highly intralinked group of topically related blogs. Bloggers Cuba also grows but its network, although progressively more integrated, follows a more hierarchical structure. In fact, La Polemica Digital remains by far the most popular node. The most interesting feature here is that La Polemica Digital itself, from 2009, starts bridging Voces Cubanas and Bloggers Cuba. Elaine Diaz is often very vocal in her posts against dissident $\operatorname{blogs} \mathrm{s}^{\mathrm{x}}$, nevertheless certain bloggers from the dissident side (i.e., Injustizia 
Notoria and Malaletra) start linking to her blog, most likely because of her popularity in the overall blogosphere. The dialogical interactions across ideological leanings within the blogosphere get more interesting in 2010, with the emergence of the partyliner La Joven Cuba, that redirects its readers to La Polemica Digital, but potentially also receives readers from Voces Cubanas blogs (i.e., via Malaletra and Ernesto). Finally, Havana Times makes a case apart because all its blogs are isolated from one another and from the remaining nodes. They rather constitute personal journals segregated from the rest of the blogosphere.

This longitudinal mapping suggests two main considerations. First, the emergence, albeit limited, of cross-ideological interactions via linking practice appears to indicate that concerns over online fragmentation (Dahlberg, 2007; Habermas, 2007; Sustein, 2001) should be reconsidered in light of the fact that ideologically opposed bloggers in certain cases do link to one another online, if not for other reasons, then simply to directly link to the sources they disagree with (Benkler, 2006: 24-27; see also Reinghold, 2007). Second, and most importantly, these network structures show potential for the emergence of a discourse network that is non-existent in statecontrolled mainstream media systems.

While this exploratory mapping of the Cuban blogosphere provides evidence of the different dynamics of its internal development and progressive shaping, it is central to notice that most of the sample blogs also provide links to external sources, that is, web pages outside the four ideological tribes_Voces Cubanas, Bloggers Cuba, Havana Times and La Joven Cuba. To provide a more comprehensive mapping of the Cuban blogosphere, the following section specifically focuses on those external sources.

\subsection{Cuban Blogosphere and its Periphery in 2012}


Figure 3 maps the Cuban blogosphere during 2012. Gray dots stand for external web pages linked by the sample blogs, their size being a measure of their in-degree. Sample blogs from Havana Times once again do not show any level of out-degree, that is, they do not link to external sources, while the rest of the blogosphere do link to several external web pages. In fact, 310 gray nodes populate the map of Figure 3, standing for news sources, organization websites, online magazines, and blogs not belonging to Voces Cubanas, Bloggers Cuba, Havana Times, or La Joven Cuba. This appears to suggest that Cuban blogging not only contributes to the early forms of Internet use as suggested by Hoffman (2011), it also enhances a more dialogical use of the Internet medium via bridging audiences from within and outside Cuba, and from different online platforms. As Etling et al. suggest "The result of this online linking behavior is a discourse network, tractable to research as a massive online corpus of text and hyperlinks. By mapping this network [...], we achieve a graphical depiction of the blogosphere imaginatively analogous to an fMRI of the social mind.” (2010: 1229). Hence, by also exploring what we may call the periphery of the blogosphere- those sources linked by but not directly belonging to the blogosphere-we can achieve a more comprehensive understanding of the overall form of Internet use represented by the act of blogging.

[Figure 3 about here]

The first interesting feature characterizing the periphery of the Cuban blogosphere is that over $40 \%$ of the web pages that receive links from the sample Cuban blogs are from outside Cuba, with the US and Spain hosting together over $23 \%$ of the total (Table 1). Most of these sources are maintained by Cuban diasporas who, therefore, expand the Cuban blogosphere abroad by building up a sort of transnational extension of the overall discourse network. Most interestingly, Cuban bloggers who contact 
diaspora bloggers potentially challenge their country's most traditional, state-dominant perceptions of culture and community, especially when those diaspora bloggers are based in the US ${ }^{\mathrm{xi}}$. In fact, "bridge blogging" in general is essential to build up interconnected communities comprising transnational populations (Zuckerman, 2007: $63)$.

The second emerging feature is that over $76 \%$ of these external sources are blogs, both personal ( $64.68 \%$ of the total) and collective $(11.52 \%$ of the total) (table 2$)$. This indicates that blogging, while indeed bridging — via linking — toward different online platforms (i.e., news websites, organization websites, online magazines, personal websites, online petitions), is emerging as a per-se online communication practice. In other words, for online Cuban audiences, the blog is an emerging medium for potential discursive interactions.

[Tables 1 and 2 about here]

To conclude, Table 3 lists the 10 most popular online external sources linked by the Cuban blogosphere, hence the 10 top online sources populating its periphery. These comprise a variety of sources from news websites to blogs, organization websites, and online magazines, hosted between Cuba, Spain, and the US.

[Table 3 about here]

The most interesting feature here is that all these sources have Cuban issues as their central focus. This suggests that the Cuban blogosphere, comprehensive of its periphery, is extremely consistent in terms of its underlying discursive practices, that is, dialogical interactions are built on the basis of shared communities of discourse and topics for online, informal debates. In other words, Table 3 provides a first insight into the actual content of the discourse network emerging in the blogosphere itself; it 
highlights how blogging provides a platform for civic interaction and-possiblypotential civic agency. The following section explores this in further detail.

\section{Bloggers and Blogging}

Bloggers' profiles may vary depending on the context where bloggers operate. For purposes of comparison, it is interesting to briefly review blogosphere demographics made available in previous studies. According to Hindman's (2009) work on the US blogosphere, US bloggers are evenly distributed between men and women, half of them are 30 years old or younger, they are more highly educated than the average population, and more than a third of them are knowledge-based professionals (2009: 104). Bloggers' demographic data in authoritarian regimes slightly vary. Etling et al.'s (2010) study of the Arabic blogosphere shows a significant gender divide, with $64 \%$ of bloggers being male. Moreover, Howard et al. suggest that in Tunisia and Egypt over $65 \%$ of the "young techno-savvy" who first took to the street and mobilized protests were under 34 (2011: 5-6).

\section{[Table 4 about here]}

Table 4 provides demographic information regarding the Cuban bloggers analyzed in this study. Data shows that over two-thirds of the bloggers are male, with their median age being between 36 and 45. The Cuban capital city of Havana hosts over two-thirds of them and while their professional background is rather varied, onefourth of them define themselves as writers or journalists. Hence, the Cuban blogosphere, similarly to the Arabic one (Etling et al. 2010), shows a significant gender divide with a prevalence of male bloggers. Cuban bloggers are slightly older than their colleagues in both the mobilized Arab world and in the US. Havana remains the center of online communities of discourse, while bloggers from cities all around the country participate to a lesser extent. The occupational background of Cuban 
bloggers is fairly varied, but similarly to their US counterpart, they are often knowledge-based professionals. In sum, the demographics of Cuban bloggers show mixed characteristics when compared to those of democratic countries (Hindman, 2009) and authoritarian contexts (Etling et al., 2010; Howard et al, 2011).

But what do Cuban bloggers blog about? In terms of general topics relevant to public life, domestic news is more popular than international news (Figure 4). Among domestic news, in terms of popularity, economic issues (86\%) are followed by political repression (70\%), women's issues (67\%), ethnic minority issues (64\%), political reform (62\%), and LGBT issues (52\%). International news and policy issues are only covered by $42 \%$ and $41 \%$ of the blogs, respectively.

[Figure 4 about here]

These data certainly show that Cuban blogs cover a wide range of societal issues with primary interest on what goes on in the country as opposed to what occurs abroad. This suggests that Cuban bloggers do participate in public discourse practices: not only they engage in diary-like online productions, they openly discuss topics relevant to a domestic social community.

[Figure 5 about here]

In terms of formal political discourse (Figure 5), bloggers most often critically discuss US (58\%) and domestic political leaders (58\%), and they debate over Cuban political prisoners $(52 \%)$. Less than $30 \%$ of the blogs cover issues relevant to the past Cuban political history, that is, the former political allies Russia and China. It is also interesting to notice that less than $10 \%$ of the blogs directly praise domestic, political leaders. These data suggest that in the Cuban blogosphere the traditional strong criticism towards US policies still holds in the political discourse, with the anti-Cuba 
economic embargo remaining at the center of the debate. However, Cuban bloggers also equally discuss and criticize domestic political leaders in the private/public dimension of their blogs. This result is extremely important because it provides direct evidence of the fact that Cuban blogs do represent an alternative to the Cuban mainstream media system: they provide a space for discussion that shows diverging features from both state-controlled and US-funded media traditionally active in the country.

\section{Discussion and Conclusion}

The questions this study has tried to approach center on the development of the Cuban blogosphere from its hidden emergence in 2007 to its 2011 official transition into the mainstream political discourse via the TV program Razones de Cuba. The analysis specifically focuses on structure, participation and content of Cuban blogging.

If we examine the Cuban blogosphere using Dalghren's (2005) public sphere dimensions, we need to highlight structural, representational, and dialogical dynamics in and among blogs. In terms of structural features, the Cuban blogosphere has initially developed around a small group of dissident blogs. Findings showed that this initial core progressively developed into an attentive cluster centered on counterrevolutionary topics, that is, informal ways of state criticisms that could not otherwise emerge in public arenas. In terms of representational and dialogical dynamics, with the emergence of other ideological streams in the Cuban blogosphere, different ideologically oriented discourse networks remained rather isolated from one another, but a few central bloggers started bridging different ideological tribes. This did not annihilate dynamics of polarization within the blogosphere, but eased the emergence of initial interactions between bloggers with contrasting political views (see also Henken, 2011). 
Data from 2012 also showed that the Cuban-based core of the blogosphere, bridges to an extended international periphery primarily made of Cuban diasporas. Structural features here provide evidence of potential dialogical pathways between Cubans within and outside the country. This part of the analysis also showed that for Cubans, blogs are a new communication genre on its own (Papacharissi 2007), since most of the blogosphere's periphery itself is made up of other personal or collective blogs, rather than different online platforms. Hence, not only do blogs serve as personal diaries, where private narratives mingle with public issues, but they also are most likely to build up specific pathways to contact other personal/private spaces structured around the same format.

In terms of informal political discourse emerging in the blogosphere, results showed that posts on domestic issues are at the core of the discourse network, far more likely to occur than those on international topics. This provides evidence of the fact that the blogosphere's overall discourse network is tightly centered on a domestic context, focused on social, cultural, and economic issues salient to the country. More specifically, when it comes to direct politics, the overall blogosphere shows interesting features. First, the Cuban blogosphere is indeed political as almost $90 \%$ of the sample blogs covered at least one of the political topics showed in Figure 5. Second, content analysis findings showed that the overall blogosphere equally criticizes domestic leaders and US anti-Cuban policies. This means that online, typically "anti-revolutionary" arguments are as likely to be represented and discussed as traditional, typically "revolutionary" arguments. Hence, the coexistence of these two major ideological stances allows for dialogical confrontations that could not otherwise occur on a different public space in Cuba. In August 2011, for instance, an interesting and rather heated debate emerged between Maria Celaya (blogger from 
Voces Cubanas) and Elaine Diaz (blogger from Bloggers Cuba) on their respective blogs, over the nature of the Cuban blogosphere and the level of political independence of different bloggers from the country ${ }^{\mathrm{xii}}$. This indicates that bloggers from different ideological backgrounds do read each other's blogs and in certain cases even interact "in remote," generating dialogical exchanges over issues that are more or less formally political.

This study suggests that a blogosphere analysis based on Benkler's (2006) structural interpretation of online linking dynamics and informed by Dalghren's (2005) threefold reframing of public sphere theory may indeed provide a suitable framework for the study of online, informal political debate in authoritarian countries. The case of the Cuban blogosphere shows that blog networks are indeed embedded in wider socio-political circumstances (Etling et al. 2010: 1240) (e.g., pre-existing structural and ideological divides), but they also generate private/public spaces hosting instances of political debate alternative to those on mainstream, controlled media outlets. The extent to which a limited, online debate may really affect the wider Cuban audience remains an open question. However, the fact that "dissident" blogs have already turned into a subject of discussion on Cuban mainstream media - as in the TV program Razones de Cuba - shows evidence that the blogosphere may indeed hide potential for offline civic agency and for changes in the country's political culture.

\section{Acknowledgements}

The author wishes to thank her Spanish speaking coders for reading and interpreting blogs: Francesca Desogus and Johanna Larenas.

\section{Funding}

This work was supported by the British Academy [grant number SG112222]

\section{Endnotes}


${ }^{\mathrm{i}}$ Available at: http://www.youtube.com/watch?v=YnCn04JJW64,

http://www.youtube.com/watch?v=i8RCowRTt c (accessed November, 2013).

ii It is important to highlight that this article does not draw upon Habermas' current position on the potential of new media to generate new public sphere dynamics (2006), but it rather focuses on the broader research agenda that aims to link Habermas' original conceptualization of the public sphere (1989[1962]) to online participatory processes.

${ }^{i i i}$ I am specifically referring to Benkler’s (2006) “networked public sphere”; Dahlgren’s (2000) “civic cultures”; De Luca and Peeples’ (2012) “public screens”; Downey and Fenton’s (2003) “counter publics”; Fraser’s (2007) “transnational public sphere”; and Papacharissi’s (2002) “virtual public sphere."

${ }^{\text {iv }}$ For instance, see Papacharissi (2008: 230-232).

${ }^{\mathrm{v}}$ Bohman similarly describes the networked structure of the Internet as supporting a "new sort of 'distributive' rather than unified public sphere with new forms of interactions" that may enable "reflexive and democratic activity" (2004: 139-140).

${ }^{\mathrm{vi}}$ Benkler specifically highlights four characteristics of network topology that allow for online participatory forms: 1) site clusters, or highly intra-linked groups of topically related sites, 2) macrolevel, strongly connected cores in the Web and blogospheres, 3) small- to medium-size site clusters, where each participating site gets more visible and star sites work as filtering backbones, and 4) small world phenomena, or the accessibility of each website via different short paths (2006: 247-248).

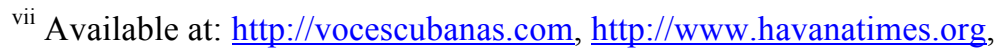
http://bloggerscuba.wordpress.com, http://lajovencuba.wordpress.com, respectively, (accessed on November, 2013).

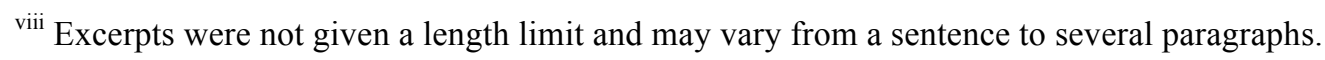

${ }^{\text {ix }}$ Calling $\mathrm{N}$ the sample size and $\mathrm{M}$ the number of links, the density of directed links is measured as $\mathrm{M} /[\mathrm{N}(\mathrm{N}-1)]$ (Granovetter, 1976: 1288). The density of links is called network cohesion and measures a network's degree of integration. In fact, a low cohesion value corresponds to a small number of links among the network nodes and a weak overall network interaction (Van Aelst and Walgrave, 2004: 117). In the case of maximum cohesion, when all network nodes are interconnected, the cohesion value is 1. ${ }^{\mathrm{x}} \mathrm{See}$, for instance, http://espaciodeelaine.wordpress.com/2011/08/04/atractor-extrano/\#more-255 (accessed November, 2013). 
${ }^{\mathrm{xi}}$ Hernandez-Reguant (2009) provides a very interesting discussion of how the first conciliatory gestures toward what in Cuba was known as the "exile community" only timidly came in the late nineties when the first bridges were built between Cubans in the island and Cubans in the US.

${ }^{\text {xii }}$ See http://espaciodeelaine.wordpress.com/2011/08/04/atractor-extrano/\#more-1255 and http://sinevasionen.wordpress.com/2011/08/22/response-to-elaines-irritation/ (accessed November, 2013).

References

Adamic L and Glance N (2005) The Political Blogosphere and the 2004 US Election: Divided They Blog. Proceedings of the 3rd international workshop on Link discovery, pp. 36-43.

Benkler J (2006) The Wealth of Networks. New Haven: Yale University Press.

Bohman J (2004) Expanding dialogue: The Internet, the public sphere and prospects for transnational democracy. In: Crossley $\mathrm{N}$ and Roberts $\mathrm{M}$ (eds.) After Habermas: New perspectives on the public sphere. Oxford: Blackwell, pp. 131-155. Chowdhury M (2008) The Role of the Internet in Burma's Saffron Revolution. Internet and Democracy Case Study Series Berkman Center Research Publication No. 2008-08. Cambridge, MA: Berkman Center for Internet and Society at Harvard University. Available at:

http://cyber.law.harvard.edu/publications/2008/Role_of the Internet in_Burmas Sa ffron_Revolution (accessed November 2013).

Dahlberg L (2001) Computer-Mediated Communication and The Public Sphere: A Critical Analysis. Journal of Computer-mediated Communication 7(1). Available at: http://jcmc.indiana.edu/vol7/issue1/dahlberg.html (accessed November 2013):

Dahlberg L (2007) Rethinking the fragmentation of the cyberpublic: from consensus to contestation. New Media and Society 9(5): 827-847. 
Dalghren P (2000) The Internet and the Democratization of Civic Culture. Political Communication 17(4): 335-340.

Dalghren P (2005) The Internet, Public Spheres, and Political Communication: Dispersion and Deliberation. Political Communication 22(2): 147162.

DeLuca KM and Peeples J (2002) From public sphere to public screen: democracy, activism, and the "violence" of Seattle. Critical Studies in Media Communication 19(2): 125-151.

Doodstar A (2004) The Vulgar Spirit of Blogging": On Language, Culture, and Power in Persian Weblogestan. American Anthropologist 106(4): 651662.

Downey J and Fenton N (2003); New Media, Counter publicity and the Public Sphere. New Media and Society 5(2): 185-202.

Emden CJ (2012) Epistemic publics. On the trading zone of knowledge. In: Emden CJ and Midgley D (eds.) Beyond Habermas: Democracy, Knowledge and the Public Sphere. New York: Berghahn Books, pp. 63-86.

Etling B, Kelly J, Faris R and Palfrey J (2009) Mapping the Arabic blogosphere: Politics, Culture and Dissent. Internet and Democracy Case Study Series Berkman Center Research Publication No. 2009-06. Cambridge, MA: Berkman Center for Internet and Society at Harvard University. Available at: http://cyber.law.harvard.edu/sites/cyber.law.harvard.edu/files/Mapping_the_Arabic_ Blogosphere_0.pdf(accessed November 2013).

Etling B, Kelly J, Faris R and Palfrey J (2010) Mapping the Arabic blogosphere: politics and dissent online. New Media Society 12: 1225-1243. 
Franzosi R (2004) From Words to Numbers. Narrative, Data, and Social Science. Cambridge: Cambridge University Press.

Fraser N (2007) Transnationalizing the Public Sphere. On the Legitimacy and Efficacy of Public Opinion in a Post-Westphalian World. Theory, Culture \& Society 24(4): 7-30.

Goldstein J (2007) The Role of Digital Networked Technologies in the Ukrainian Orange Revolution Research Publication No. 2007-14. Cambridge, MA: Berkman Center for Internet and Society at Harvard University. Available at: http://cyber.law.harvard.edu/publications/2007/The_Role_of_Digital_Networked_Te chnologies_in_the_Ukranian_Orange_Revolution (accessed November 2013):

Granovetter M (1976) Network sampling: some first steps The American Journal of Sociology 81(6): 1287-1303.

Habermas J (1989[1962]) The Structural Transformation of the Public Sphere: An Inquiry into a Category of a Bourgeois Society. Cambridge, MA: MIT Press.

Habermas J (2006) Political Communication in Media Society: Does Democracy Still Enjoy an Epistemic Dimension? The Impact of Normative Theory on Empirical Research Communication Theory 16: 411-426.

Henken T (2011) A Bloggers' Polemic: Debating Independent Cuban Blogger Projects in a Polarized Political Context. Proceedings of the Twenty-First Annual Meeting Association for the Study of the Cuban Economy (ASCE). Miami, Florida August 4-6, 2011. Available at: http://www.ascecuba.org/publications/proceedings/volume21/pdfs/henken.pdf (accessed November 2013). 
Hernandez-Reguant A (2009) Multicubanidad. In: Hernandez-Reguant A (ed.) Cuba in the Special Period. Culture and Ideology in the 1990s. New York: Palgrave MacMillan, pp. 69-88.

Herring SC, Kouper I, Paolillo JC, Scheidt LA and Tyworth M (2005) Conversations in the Blogosphere: An Analysis "From the Bottom Up". Proceedings of the Thirty-Eighth Hawai'i International Conference on System Sciences (HICSS38). Los Alamitos: IEEE Press.

Hindman M (2009) The Myth of Digital Democracy. Princeton: Princeton University Press.

Hoffman B (2011) Civil society 2.0? How the internet changes state society relations in authoritarian regimes: the case of Cuba. GIGA working papers, No. 156. Available at: http://hdl.handle.net/10419/47847 (accessed November 2013).

Howard PN, Duffy A, Freelon D, Hussain M, Mari W, Mazaid M, (2011) Opening closed regimes. What was the role of social media during the Arab spring? Project on Information Technology and Political Islam. Working Paper 1. Available at: http://pitpi.org/index.php/2011/09/11/opening-closed-regimes-whatwas-the-role-of-social-media-during-the-arab-spring/ (accessed November 2013).

ITU (2012) Measuring The Information Society. Geneva, Switzerland. Kalathil S and Boas TC (2003). Open Networks, Closed Regimes. The Impact of the Internet on Authoritarian Rule. Washington: Carnegie Endowment for International Peace.

Kelly S, Cook S, and Truong M (2012) Freedom on the Net 2012. A Global Assessment of Internet and Digital Media. Washington, DC: Freedom House, September 24, 2012. Available at: 
http://www.freedomhouse.org/sites/default/files/FOTN\%202012\%20FINAL.pdf (accessed November 2013).

King G, Pan, J and Roberts ME (in press) How Censorship in China Allows Government Criticism but Silences Collective Expression. American Political Science Review.

Moe H (2011) Mapping the Norwegian Blogosphere: Methodological Challenges in Internationalizing. Social Science Computer Review 29(3): 313-326. Morozov E (2009a) Moldova's Twitter Revolution. Foreign Policy. Available at: http://neteffect.foreignpolicy.com/posts/2009/04/07/moldovas_twitter_revolution (accessed November 2013).

Morozov E (2009b) More Analyses on Twitter role in Moldova. Net Effect. Available at:

http://neteffect.foreignpolicy.com/posts/2009/04/07/more analysis_of twitters role in_moldova (accessed November 2013).

Morozov E (2009c) Iran: Downside to the "Twitter Revolution". Dissent 56(4): 10-14.

Morozov E (2011) The Net Delusion. How Not to Liberate the World. London: Penguin Books.

Noam EM (2005) Why the Internet is Bad for Democracy. Communications of the ACM 48(10), pp. 57-58. Available at: http://www.elinoam.com/eli/internet_democracy.pdf (accessed November 2013). Papacharissi Z (2002) The virtual sphere. The Internet as a public sphere. New Media and Society 14(1): 9-27. 
Papacharissi Z (2007) Audiences as Media Producers: Content Analysis of 260 Blogs. In: Tremayne M (ed.) Blogging, Citizenship, and the Future of Media. London: Routledge, pp. 21-38.

Papacharissi Z (2008) The virtual sphere 2.0. The Internet, the public sphere, and beyond. In: Chadwick A and Howard PN (eds.) Routledge Handbook of Internet Politics. London: Routledge, pp. 230-245.

Park HW and Kluver R (2009) Affiliation in political blogs in South Korea: Comparing online and offline social networks. In: Goggin G. and McLelland M (eds.) Internationalizing Internet studies. New York, NY: Routledge, pp. 252-265.

Price R (2011) New Media's New Literature. Review: Literature and Arts of the Americas 44(1): 39-46.

Radsch C (2008) Core to Commonplace: The evolution of Egypt's blogosphere. Arab Media and Society 6. Available at: http://www.arabmediasociety.com/?article=692 (accessed November 2013).

Rahimi B (2011) The Agonistic Social Media: Cyberspace in the Formation of Dissent and Consolidation of State Power in Postelection Iran. The Communication Review 14(3): 158-178.

Rheingold H (2007) Habermas blows off question about the Internet and the Public Sphere In: SmartMob. Available at: http://www.smartmobs.com/ (accessed November 2013).

Schneider SM (1997) Expanding the public sphere through computermediated communication: Political discussion about abortion in a Usenet newsgroup. $\mathrm{PhD}$ Thesis, MIT, US. Available at: https://people.sunyit.edu/ steve/main.pdf (accessed November 2013). 
Sustein CR (2009) Republic.com 2.0. Princeton: Princeton University

Press.

Van Aelst P and Walgrave S (2004) New Media, new movements?

The role of the internet in shaping the 'anti-globalization' movement. In: Van de

Donk et al. (eds.) Cyberprotest. New media, citizens and social movements. London:

Routledge, pp. 97-122.

Woo-young C and Park HW (2012) The Network Structure of the

Korean Blogosphere. Journal of Computer-Mediated Communication 17: 216-230.

Zhuo X (2009) The political blogosphere in China: A content analysis

of the blogs regarding. New Media Society 11: 1003-1022.

Zuckerman E (2008) Meet the bridgebloggers. Public Choice 134:

$47-65$. 


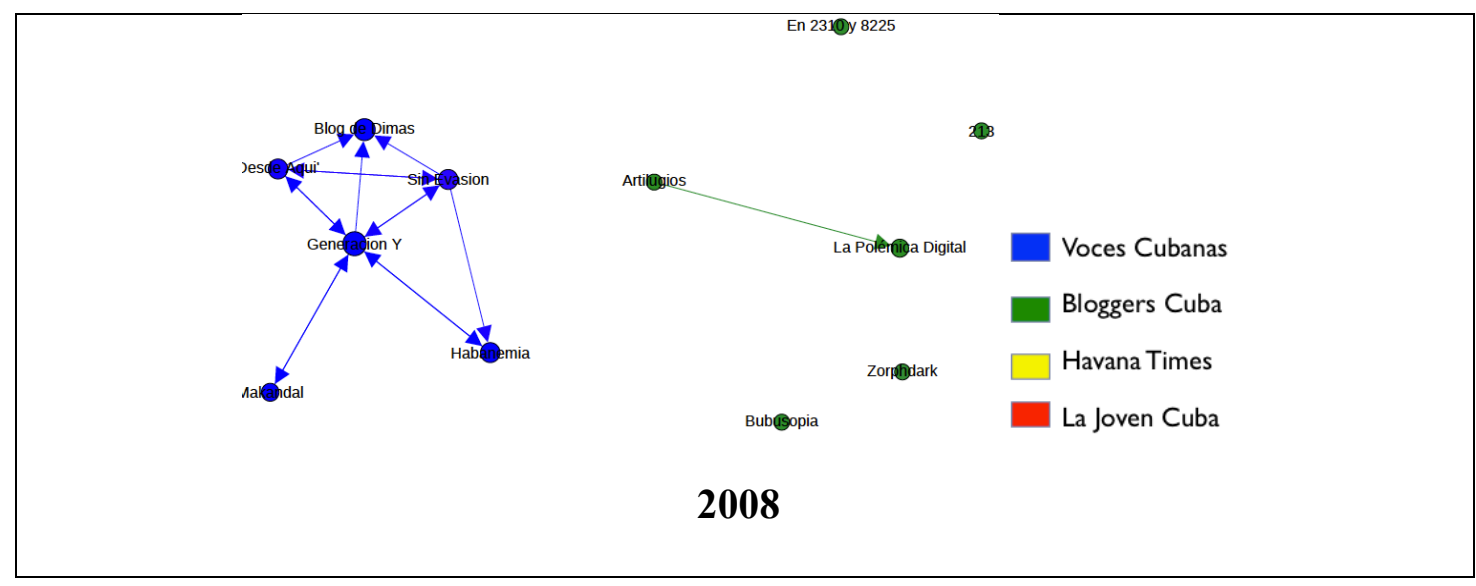

Figure 1 Longitudinal Mapping, 2008 


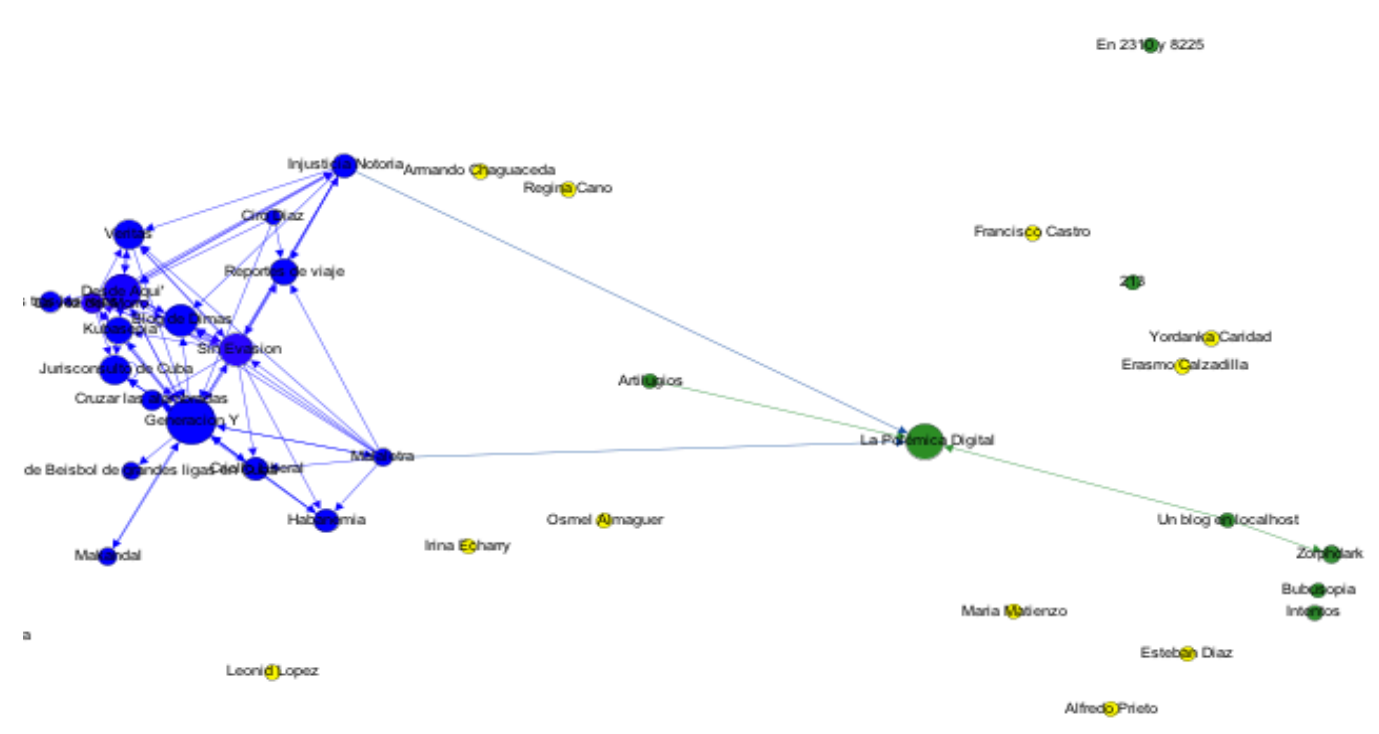

Voces Cubanas

Bloggers Cuba

$\square$ Havana Times

La Joven Cuba

2009

En $2310 y$ 8225

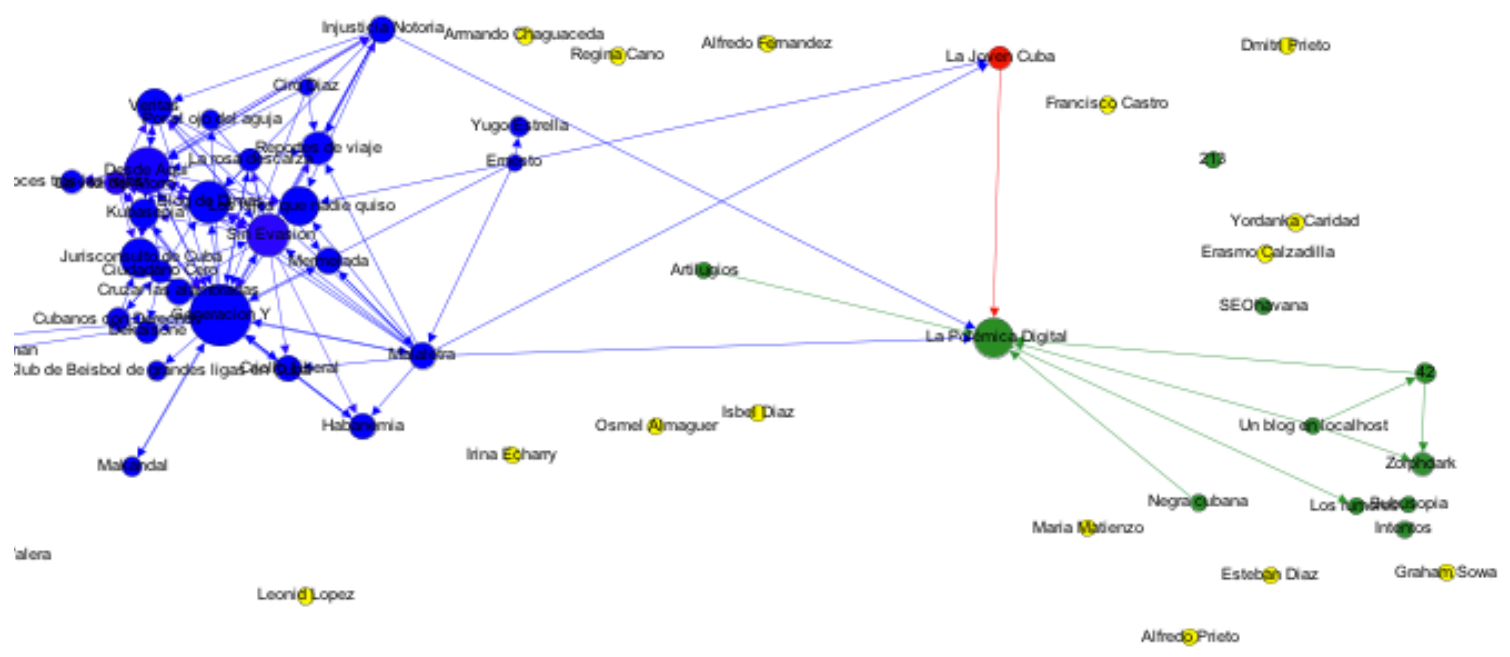




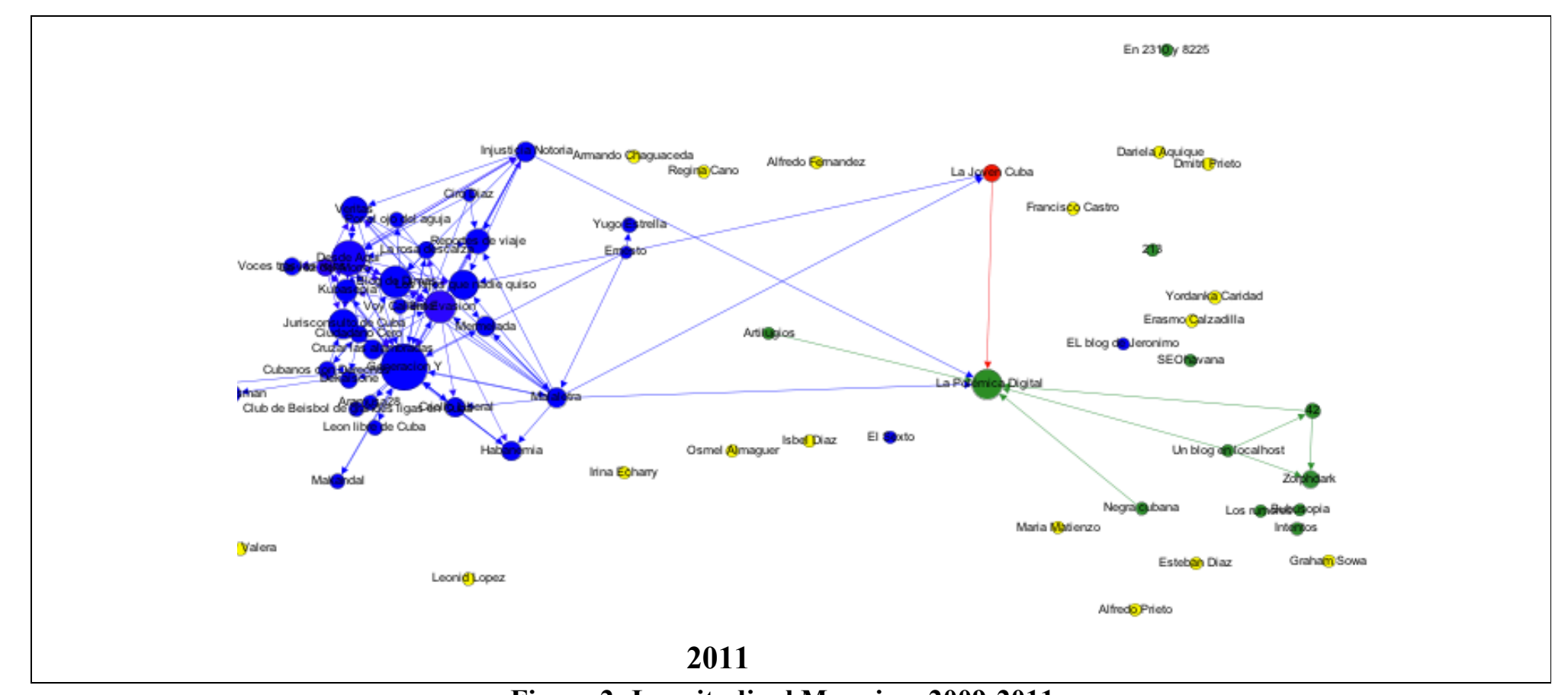

Figure 2: Longitudinal Mapping, 2009-2011 


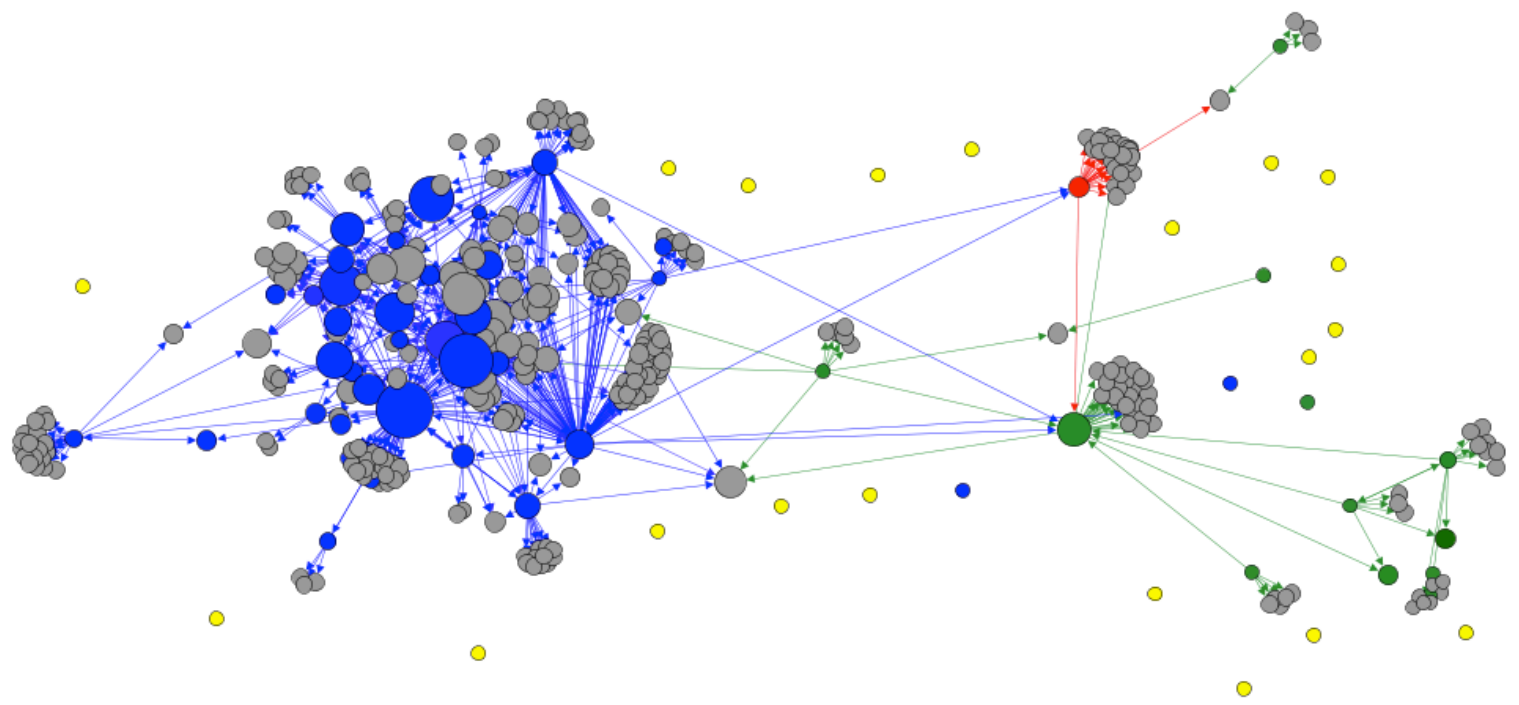

Figure 3: Cuban Blogosphere and its Periphery 


\begin{tabular}{|l|c|}
\hline Outlink location & \\
\hline Cuba & $43.12 \%$ \\
\hline US & $14.13 \%$ \\
\hline Abroad (but & \\
\hline specified) & $9.29 \%$ \\
\hline Spain & $8.92 \%$ \\
\hline Germany & $1.49 \%$ \\
\hline mix (from Cuba & \\
and abroad) & $1.49 \%$ \\
\hline Sweden & $1.49 \%$ \\
\hline Canada & $1.12 \%$ \\
\hline UK & $0.74 \%$ \\
\hline Australia & $0.37 \%$ \\
\hline Brazil & $0.37 \%$ \\
\hline China & $0.37 \%$ \\
\hline France & $0.37 \%$ \\
\hline Italy & $0.37 \%$ \\
\hline Norway & \\
\hline Peru' & \\
\hline Switzerland & \\
\hline Total & \\
\hline
\end{tabular}

Table 1: Outlink location

\begin{tabular}{|l|c|}
\hline \multicolumn{1}{|c|}{ Outlink type } & \\
\hline personal blog & $64.68 \%$ \\
\hline collective blog & $11.52 \%$ \\
\hline news website & $8.18 \%$ \\
\hline organisation & \\
website & $8.18 \%$ \\
\hline online & $3.72 \%$ \\
\hline magazine & $1.86 \%$ \\
\hline blog platform & $1.12 \%$ \\
\hline personal & $0.74 \%$ \\
\hline website & 100.00 \\
\hline petition & \\
\hline Total & \\
\hline
\end{tabular}

Table 2: Outlink Type 


\begin{tabular}{|c|c|c|c|c|}
\hline Label & In-Degree & Address & Type & Location \\
\hline $\begin{array}{l}\text { Penultimos } \\
\text { dias }\end{array}$ & 10 & http://www.penultimosdias.com & news website & Spain \\
\hline Convivencia & 6 & http://www.convivenciacuba.es & $\begin{array}{l}\text { online } \\
\text { magazine }\end{array}$ & Cuba \\
\hline $\begin{array}{l}\text { Mi isla al } \\
\text { mediodia }\end{array}$ & 6 & http://isla12pm.blogspot.co.uk & personal blog & Cuba \\
\hline Retazos & 6 & http://www.desdecuba.com/retazos & personal blog & $?$ \\
\hline $\begin{array}{l}\text { Diario de } \\
\text { Cuba }\end{array}$ & 5 & http://www.diariodecuba.com & news website & $\begin{array}{l}\text { mix (from } \\
\text { Cuba and } \\
\text { abroad) }\end{array}$ \\
\hline Guama' & 5 & http://el-guama.blogspot.co.uk/ & collective blog & $?$ \\
\hline $\begin{array}{l}\text { Proyecto } \\
\text { Varela }\end{array}$ & 5 & http://www.oswaldopaya.org/es & personal blog & Cuba \\
\hline $\begin{array}{l}\text { Asociacion } \\
\text { Damas de } \\
\text { blanco }\end{array}$ & 4 & http://www.damasdeblanco.org & $\begin{array}{l}\text { organisation } \\
\text { website }\end{array}$ & Spain \\
\hline Babalu blog & 4 & http://babalublog.com & collective blog & US \\
\hline Cafe Fuerte & 4 & http://cafefuerte.com & news website & US \\
\hline
\end{tabular}

Table 3: 10 Top Outlinks 


\begin{tabular}{|c|c|c|c|c|c|c|c|c|}
\hline \multicolumn{2}{|c|}{ Gender } & \multicolumn{2}{|r|}{ Age } & \multicolumn{2}{|c|}{ City } & \multicolumn{3}{|c|}{ Occupation } \\
\hline Male & $63.64 \% \quad(42)$ & $18-24$ & $7.58 \%$ & La Habana & $68.18 \% \quad(45$ & Writer/journalist & $25.76 \%$ & (17) \\
\hline Female & $30.30 \% \quad(20)$ & $25-35$ & $28.79 \%$ & Santa Clara & $4.55 \%$ & Student & $9.09 \%$ & (6) \\
\hline Couple & $3.03 \% \quad(2)$ & $36-45$ & $27.27 \%$ & Camagüey & $1.52 \%$ & Artist & $6.06 \%$ & (4) \\
\hline n.a. & $3.03 \% \quad(2)$ & $46-60$ & $21.21 \%$ & $\begin{array}{l}\text { Ciego de } \\
\text { Ávila }\end{array}$ & $1.52 \%$ & Teacher & $6.06 \%$ & (4) \\
\hline & & $60+$ & $6.06 \%$ & Holguin & $1.52 \%$ & Multiple jobs & $4.55 \%$ & (3) \\
\hline & & n.a. & $9.09 \%$ & La Lisa & $1.52 \%$ & Web designer & $4.55 \%$ & (3) \\
\hline & & & & Matanzas & $1.52 \% \quad(1)$ & Artisan & $3.03 \%$ & (2) \\
\hline & & & & $\begin{array}{l}\text { Santa Cruz } \\
\text { del Norte }\end{array}$ & $1.52 \%$ & Priest & $3.03 \%$ & (2) \\
\hline & & & & Palmira & $1.52 \%$ & Architect & $1.52 \%$ & (1) \\
\hline & & & & n.a. & $16.67 \% \quad(11)$ & Chemist & $1.52 \%$ & (1) \\
\hline & & & & & & $\begin{array}{l}\text { Construction } \\
\text { Foreman }\end{array}$ & $1.52 \%$ & (1) \\
\hline & & & & & & Cook & $1.52 \%$ & (1) \\
\hline & & & & & & Editor & $1.52 \%$ & (1) \\
\hline & & & & & & Entertainer & $1.52 \%$ & \\
\hline & & & & & & Lawyer & $1.52 \%$ & \\
\hline & & & & & & Medical doctor & $1.52 \%$ & \\
\hline & & & & & & Professor & $1.52 \%$ & (1) \\
\hline & & & & & & n.a & $24.24 \%$ & (16) \\
\hline
\end{tabular}

Table 4: Bloggers' Census 


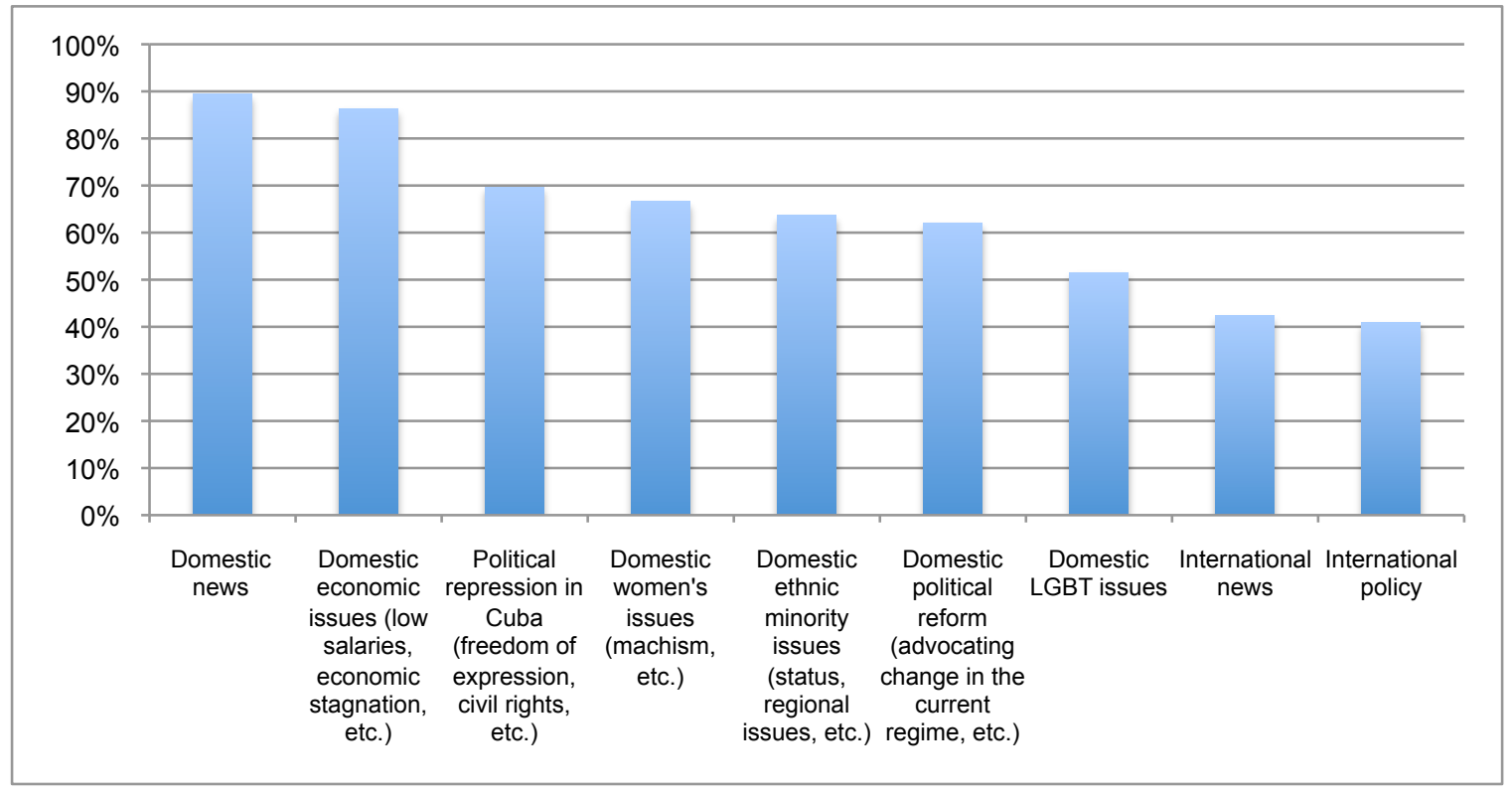

Figure 4: General Topics 


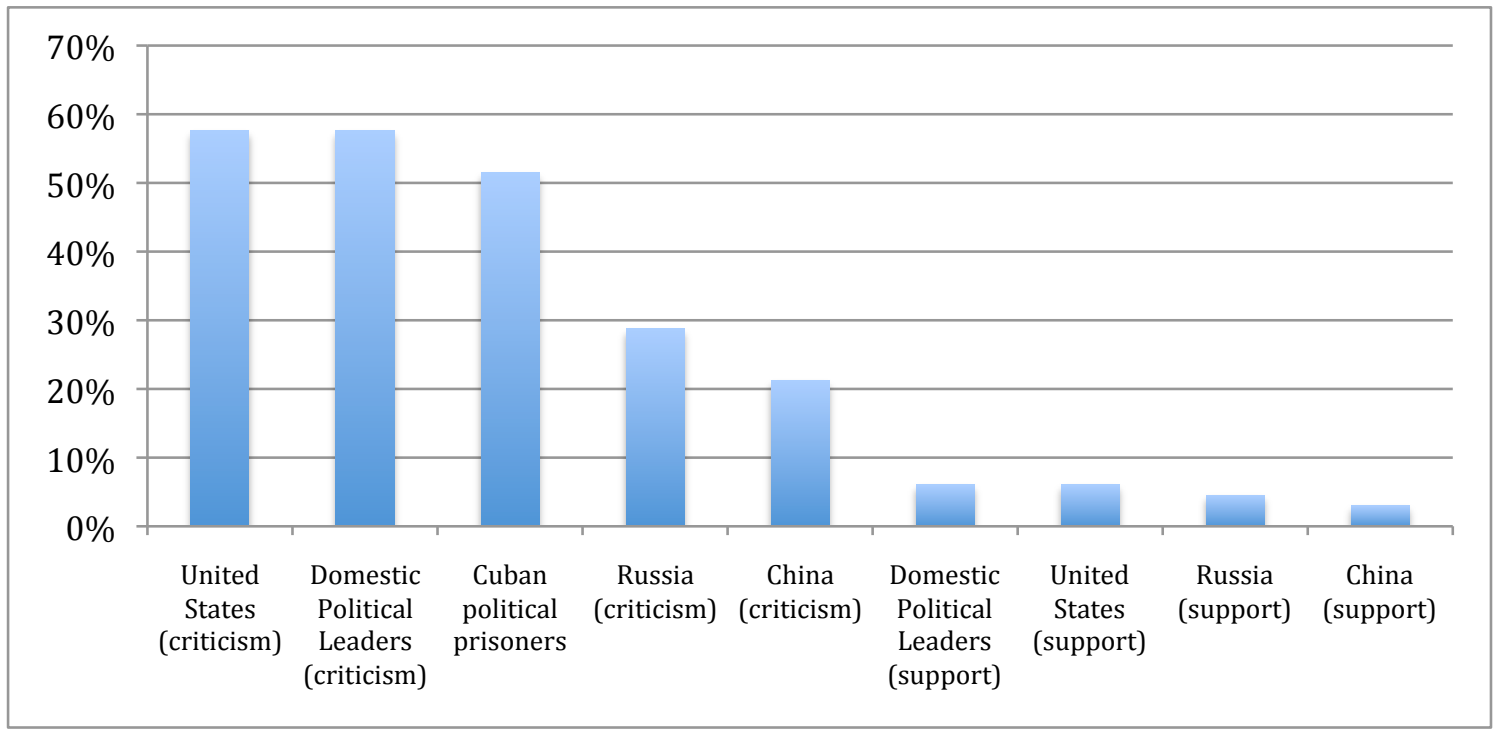

Figure 5: Specific Topics/ Politics 